\title{
ELABORAÇÃO DE NUGGETS COM A POLPA DO CAMARÃO Litopenaeus vannamei E SEUS COMPOSTOS NUTRICIONAIS
}

Katherine Saldanha NOLETO ${ }^{1}$; Jéssica Adriane Leite Sousa SOARES ${ }^{1}$; Jeysa Talita Costa de

SOUSA $^{1}$; Priscila Cantanhede Araujo BARROS ${ }^{1}$; Leonildes Ribeiro Nunes ${ }^{1}$ e Elaine Cristina Batista dos SANTOS ${ }^{2}$

${ }^{1}$ Engenheira de Pesca- Universidade Estadual do Maranhão

2 Doutora em Engenharia de Pesca- Universidade Estadual do Maranhão

*email: katherinenoleto@gmail.com

Recebido em 23/08/2017

Resumo - Este trabalho teve como objetivo realizar um novo subproduto a base de pescado com alto valor nutricional, utilizando a espécie exótica Litopenaeus vannamei na elaboração de nuggets, a fim de contribuir para diversificação tecnológica na indústria do pescado. A pesquisa foi realizada na Universidade Estadual do Maranhão, na qual o camarão foi processado e condimentado. Foram realizadas as análises físico-químicas deste produto, para ser observado seu valor nutricional através dos níveis de umidade, lipídio, proteína e minerais pertencentes nesse alimento e foram feitas também as análises microbiológicas, para comprovar o grau de higiene no preparo e consumo deste alimento. Por fim, foram avaliados os níveis de aceitação do produto pronto para o consumidor, utilizando testes sensoriais. De acordo com a escala hedônica, previamente estruturada, que vai do adorei com até o detestei, os resultados obtidos foram de apenas duas categorias, que foi o adorei com $46,67 \%$ e o gostei com 53,33\%. Pôde-se concluir que este alimento oferece um sabor agradável ao consumidor e praticidade de preparo, podendo contribuir para um aumento significativo no consumo do pescado.

Palavras-Chave: Diversificação tecnológica, Teste sensorial, Feira

\section{NUGGETS OF PREPARATION WITH THE PULP OF THE SHRIMP LITOPENAEUS VANNAMEI}

Abstract - This study aimed, perform a new by-product of fish on base with high nutritional value, using the exotic species Litopenaeus vannamei in developing nuggets in order to contribute to technological diversification in the fishing industry. The research was conducted at the State University of Maranhao, where the shrimp was processed and spicy. the physicochemical analysis of this product were carried out, to be observed its nutritional value through the humidity levels, lipid, protein and minerals belonging to this food and were also made microbiological analyzes to prove the standard of hygiene in the preparation and consumption of this food. Finally we evaluated the product acceptance levels ready for the consumer using sensory tests. According to previously hedonic scale from loved up to the hated and the results were only two categories that was loved with $46,67 \%$ and enjoyed with $53.33 \%$. It was concluded that this food has a pleasant flavor to the consumer and practicality of preparation, may contribute to a significant increase in fish consumption.

Keywords: Technological diversification, Sensory test, Fair 


\section{INTRODUÇÃO}

O consumo de pescado no Brasil é considerado baixo se comparado aos demais produtos de origem animal, correspondendo a $5 \%$ apenas, sendo os demais, frango 43\%, suínos $12 \%$, bovinos 39\%. (CARVALHO; LEMOS, 2009).

A produção mundial do camarão, cultivado em mais de 50 países emergentes em 2003, chegou a 1630.000 toneladas, ou seja, 35,3\% do total de camarões produzidos em todo o mundo, cujo volume anual, considerando captura e cultivo, foi de 4630.000 toneladas (ABCC, 2004).

O camarão L. vannamei se caracteriza por ser uma espécie nativa da costa sul americana do Oceano Pacífico, indo do Peru ao México, com acentuada predominância na faixa costeira do Equador, sendo cultivado em todos os países produtores de camarão do mundo ocidental (MAGALHÃES, 2004).

A tecnologia para a produção de novas formas de consumo do pescado vem apresentando um rápido e representativo crescimento, uma vez que em virtude da correria do dia a dia se tem buscado formas de alimentação, que sejam saudáveis, mas que ao mesmo tempo apresentem praticidade (PINTO, 2014).

As inovações tecnológicas e científicas no último século possibilitaram uma grande industrialização nos países. Associado à globalização, a indústria de alimentos teve seu ritmo produtivo acelerado, conseguindo produzir diferentes tipos de produtos em pequeno intervalo de tempo. Isso ocorreu, simultaneamente, com a necessidade da população em ter produtos que exigissem pouco tempo de preparo e que satisfizessem seus anseios individuais (ENES; SLATER, 2010; FERREIRA; AYDOS, 2010).

Dados da Associação Brasileira das Indústrias da Alimentação (ABIA) mostram que o crescimento das vendas e dos investimentos no mercado interno têm se mantido constantes, até mesmo à revelia da desaceleração econômica. Segundo a ABIA, o faturamento acumulado no setor "Food Service", em 2013, foi de 100,5 bilhões de reais. Pesquisa do Instituto Brasileiro de Geografia e Estatística (IBGE) mostrou que o brasileiro destinou ao "Food Service" 31,2\% de seus gastos com alimentos em 2010 (ABIA, 2013; IBGE, 2011).

Tendo em vista que os consumidores buscam produtos de qualidade que ofereçam praticidade no seu preparo, a produção do nuggets de camarão ou empanado de camarão industrializado, pode aumentar a variabilidade da indústria de beneficiamento e facilitar a vida do consumidor, sendo um produto vendido pré-pronto, oriundo de uma espécie exótica, porém cultivada no território nacional e de fácil aceitabilidade pela população brasileira. 


\section{MATERIAL E MÉtodos}

Para a realização do experimento foi utilizado camarão L. Vannamei, adquirido na feira do bairro de São Luís-MARANHÃO, com os quais foram realizados procedimentos de descabeçamento, limpeza, pesagem, processamento e, em seguida, esse camarão processado foi condimentado, e transformados em nuggets.

Após a obtenção da polpa homogênea, foram adicionados condimentos e farinha de trigo, na farinha de aveia, em ovos para proporcionar consistência, em seguida, esta massa foi moldada na hamburgueira e dividida em quatro pedaços (molde padrão comercial para nuggets). E, assim, estes foram empanados em ovos batidos e farinha de rosca. Posteriormente, os nuggets já prontos, foram embalados em pratos descartáveis e recobertos com papel filme, sendo assim armazenados e acondicionados no congelador para, em seguida, serem preparados para consumo através da fritura e levados aos testes físico-químicos, microbiológico e sensorial.

Em seguida, foram realizadas as análises físico-químicas, que consistiram nas seguintes análises:

Umidade (UM): foi aplicado o método de gravimétrico descrito pela Association of Official Anlytical Chemists - A.O.A.C. (2000).

Proteína bruta (PB): foi quantificada pelo método de micro Kjedahl para determinar o nitrogênio total, conforme exposto a AOAC (2000), Silva e Querioz (2004) e Fogaça et. al. (2009).

A gordura foi extraída pelo método de Bligh Dayer adaptado e o conteúdo de cinzas determinado por meio de incineração em mufla a $550^{\circ} \mathrm{C}$, por 5 horas, já as análises de carboidratos foram realizadas por diferença.

Etapa microbiológica:

Testes microbiológicos foram realizados no produto final, ou seja, os nuggets de camarão, esta etapa ocorreu no laboratório de microbiologia-UEMA, e nestes testes se determina a presença ou ausência de Salmonella, Staphylococus aureus, e Coliformes totais.

Etapa sensorial:

O teste sensorial foi realizado com a escala hedônica e testado através do paladar de 15 provadores escolhidos aleatoriamente, e assim realizado teste de aceitabilidade, que teve duas qualificações, a primeira se tratava do sabor, em que a nota variava de um (adorei) a cinco (detestei), a segunda qualificação relacionada ao consumo, tendo nota de um (comeria sempre) a 
cinco (nunca comeria), levando em conta o aroma, o sabor, a cor e a textura.

A escala hedônica é um teste utilizado, no qual se mede o nível de preferência de produtos alimentícios por consumidores, relatando a opinião sobre o alimento, quanto ao gostar ou não gostar. Esta avaliação é convertida em escores numéricos, podendo ser analisados estatisticamente para determinar a diferença no grau de preferência entre amostras (IFT, 1981; LAND; SHEPHERD, 1988; ABNT, 1998).

\section{RESULTADOS E DISCUSSÃO}

A composição centesimal dos nuggets de camarão L. vannamei foi de extrema importância para se saber sobre: umidade, cinzas, proteínas, lipídios e carboidratos (Tabela 1) pertencentes neles e, assim, identificar a qualidade deste alimento para o consumo da população, ocasionando o consumo deste subproduto, por crianças e por adultos.

Tabela 1. Composição centesimal dos nuggets de camarão

\begin{tabular}{lr}
\hline Umidade (\%) & 66,94 \\
Proteína (\%) & 15,39 \\
Lipídio(\%) & 1,94 \\
Cinzas(\%) & 1,00 \\
Carboidrato(\%) & 14,73 \\
\hline
\end{tabular}

O subproduto apresentou elevada umidade 66,94\% (Tabela 2), características comuns do pescado e que propicia uma rápida deterioração, por isso, o pescado é conhecido como alimento perecível, podendo trazer risco para a saúde do consumidor se não tiver a qualidade e a conservação adequada (MOURA ET AL, 2003).

Valores de 75,10\% de umidade foram encontrados na carne do camarão L. vannamei in natura por SEABRA, comprovando que a umidade encontrada no nugget de camarão está em sua quantidade normal devido esse subproduto ser composto por uma grande quantia da carne de camarão L. vannamei in natura, então, os cuidados com a conservação desse alimento devem ser de alto grau, cumprindo as normas da ANVISA para a boa conservação. E quantidades menores de umidade foram encontradas por Santos, 2013, com exatos 44, 36\% para nuggets de tilapia no Nilo (Oreacromus Niloticus), comprovando que podem ser encontradas umidades mais baixas para peixes.

O teor de proteína $15,39 \%$ foi muito bom ao ser comparado com resíduo desidratado de camarão de espécie não identificada de Fanimo et al. (2000), com um valor de 12,94\% e superior também a Freitas et al. com um valor de 7,46\% para a farinha da casca do camarão-sete-barbas, 
ficando um pouco abaixo apenas pelo valor encontrado por SEABRA, 20,46\% na carne in natura do L. vannamei, comprovando que o processo de beneficiamento não afeta, de forma significativa, na composição da proteína pertencente a esse alimento, comprovando que este alimento tem um alto valor proteico em sua composição nutricional.

O teor de cinzas foi de 1,0\%, encontrado nos nuggets de camarão e levando em consideração os valores da composição centesimal do L. vanamei in natura, o qual apresentou teor de cinzas de $1,76 \%$ (SEABRA), pode-se afirmar que os ingredientes utilizados na fabricação dos nuggets não afetaram, de forma significativa, na eliminação dos minerais encontrados na carne do camarão, proporcionando um alimento rico em minerais para o consumo humano.

O teor de lipídios contidos nos nuggets foi de exatos $1,94 \%$ e comparando com o teor lipídico encontrado na carne do L. vannamei in natura por SEABRA 0,26\% e 2,01\% no cefalotórax do L. vannamei por Damasceno, esse subproduto oriundo da carne de camarão L. vannamei está dentro de um padrão necessário e seguro para o consumidor, devido o camarão ser um tipo de pescado, a gordura pertencente a ele é uma gordura saudável e mesmo com os acréscimos dos ingredientes, esse subproduto continuou com uma porcentagem baixa de gordura, ocasionando um alimento saudável para o consumo de crianças e de adultos.

Carboidratos são açúcares abundantes em alimentos. O conteúdo de carboidratos do pescado foi dado como carboidratos totais pela diferença, ou seja, é o somatório das porcentagens de umidade (A), proteínas (B), lipídios (C) e cinzas (D) subtraídas de 100 (AVELAR, 2013). De acordo com a IN 6 (BRASIL, 2001), o valor estimado de consumo de carboidrato para nuggets é de até $30 \%$, no qual se comprova que esse alimento está dentro dos padrões para uma alimentação saudável, não contendo risco para a saúde humana.

Os resultados das análises microbiológicas, expressos na Tabela 2, realizados nas amostras de nuggets mostraram a ausência de Salmonela e Coliformes totais, comprovando a eficácia e higiene na hora da elaboração do produto.

Tabela 2. Análise microbiológica do nuggets de L. vannamei

\begin{tabular}{cc}
\hline Quantidade $(\mathrm{g})$ & $25 \mathrm{~g}$ \\
\hline Salmonella & Ausente \\
Staphylococcus & Ausente \\
Coliformes & Ausente \\
\hline
\end{tabular}

Em análises precedidas após o teste sensorial, que foi realizado com os alunos da Universidade Estadual do Maranhão ficou comprovado aceitação máxima dos consumidores devido à escolha em apenas dois itens da escala hedônica, sendo: o adorei com $46,67 \%$ e o gostei com $53,33 \%$, em que cerca de $80 \%$ 
dos consumidores querem manter um consumo constante e cerca de $20 \%$ dos consumidores querem manter um consumo esporádico. Devido à aceitação com a maior frequência de consumo ser bem mais elevada que a aceitação com um consumo esporádico, relatada pelo teste sensorial, pode-se afirmar que o nugget de camarão é um alimento viável para a industrialização e que ao ser comparado com os nuggets de tilápia com adição de linhaça, que teve uma aceitabilidade de mais de 70\% pelos consumidores (ROSA, 2012), pode-se constatar que este é um alimento saudável e que será consumido, em grande potencial, levando em consideração a opinião dos consumidores devido o sabor, a aparência, os nutrientes contidos no pescado e, também, a facilidade no seu preparo.

A Análise Sensorial é uma ferramenta chave não apenas no desenvolvimento de novos produtos como também, na seleção e caracterização de matérias-primas, no estudo da vida de prateleira do alimento (shelflife), na identificação das preferências dos consumidores, por um determinado produto e, finalmente, na seleção dos sistemas de envase e das condições de armazenamento para a melhoria da qualidade (ONOYAMA, 2006).

Observa-se que os nuggets de camarão foram muito bem aceitos como mostra na Figura 1. Dessa forma, no quesito de aceitabilidade a maioria optou pelo gostou e adorou e no quesito de frequência de consumo, uma vez que a maioria comeria sempre, devido seu sabor, cor e cheiro serem bastante agradáveis.

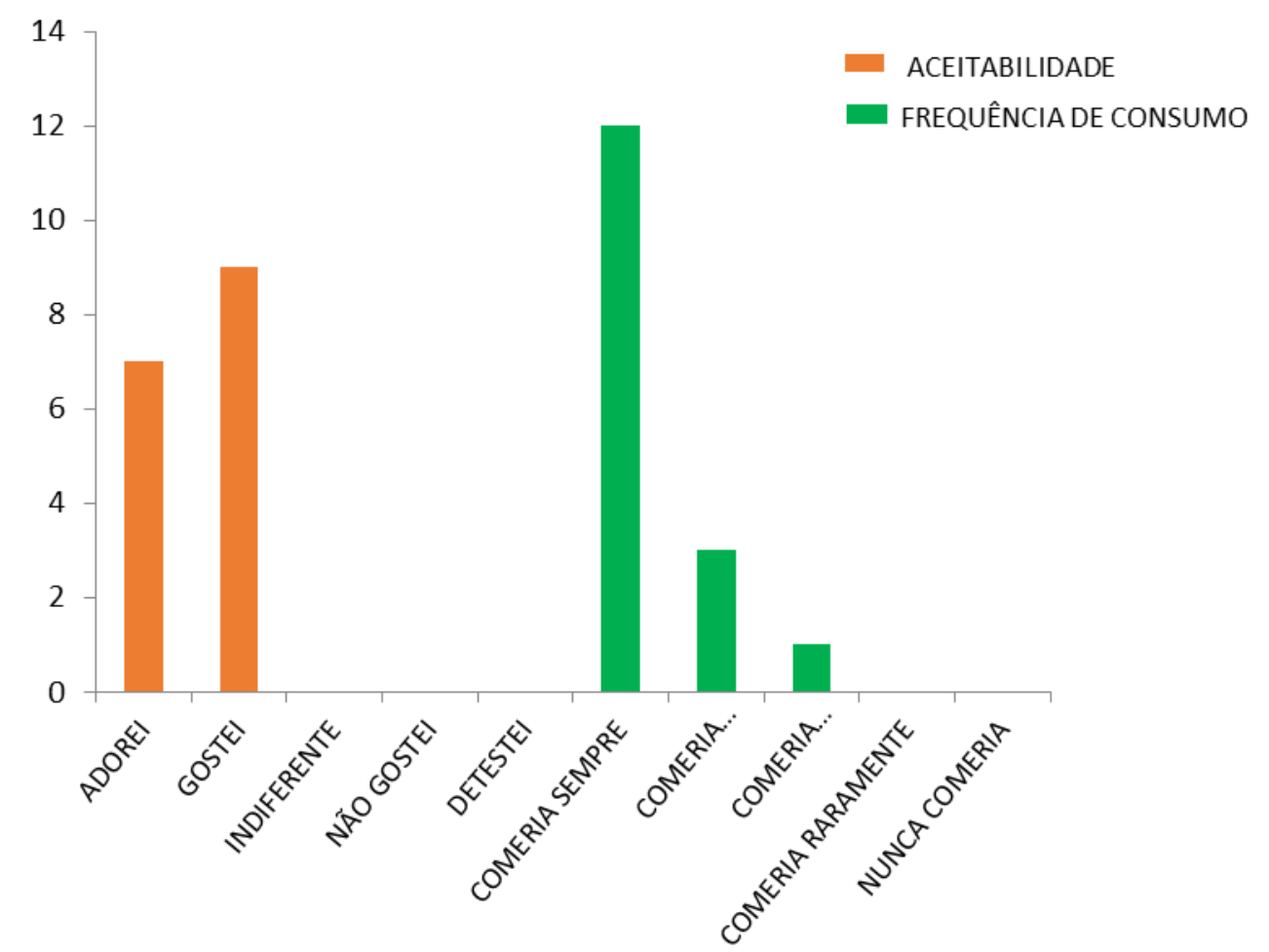

Figura 1. Teste de aceitabilidade e frequência de consumo dos nuggets de camarão 


\section{CONCLUSÕES}

Este estudo mostra através de análises físico-químicas que esse subproduto a base de camarão L. vannamei tem um teor de umidade, de proteína, de lipídeo, de carboidrato e de minerais necessários para uma alimentação balanceada e saudável. Também comprovou através das análises microbiológicas que este alimento está isento de micro-organismos, através do controle sanitário no momento do preparo e, por fim, as análises sensoriais mostram que houve uma grande aceitabilidade, em todos os quesitos da escala hedônica, mostrando claramente a intenção de consumo pelos provadores desse subproduto.

\section{REFERÊNCIAS}

ABCC, 2004. Associação brasileira de criadores de camarão. Acessado em 12 de junho de 2015 em http://abccam.com.br/site/wp-content/uploads/2013/12/Dimens\%C3\%A3o-da-Cadeia-Produtiva-daCarcinicultura-Brasileira-JUN-2012.pdf.

ABNT. Associação Brasileira De Normas Técnicas. NBR 14141: escalas utilizadas em análise sensorial de alimentos e bebidas. Rio de Janeiro. 1998.

ASSOCIAÇÃO BRASILEIRA DAS INDÚSTRIAS DA ALIMENTAÇÃO - ABIA. O setor em números: Mercado interno. 2013. Disponível em: < http://www.abia.org.br/vst/vendas.pdf>. Acesso em: 02 out. 2013.

CARVALHO, R., LEMOS, D. 2009. Aquicultura e consumo de carnes no Brasil e no Mundo. Revista Panorama da Aqüicultura, Rio de Janeiro, v. 19, n. 112, março/abril.

DAMASCENO. FARINHA DOS RESÍDUOS DE CAMARÃO L. VANNAMEI: Caracterização e utilização na formulação de hambúrguer. Disponível em http://repositorio.ufpe.br/bitstream/handle/123456789/8894/arquivo8600_1.pdf?sequence=1\&isAllo wed=y. Acesso em 29 de Setembro 2016.

SOUZA; BITENCOURT; GOMES; OLIVEIRA; SANTOS; REIS; NUNES; NARAIN. Desenvolvimento e caracterização físico-química e sensorial de nuggets formulados com concentrado protéico de pescado- MARINE BEEF. Disponível em file://C:/Users/kathe/Downloads/140-502-1-PB.pdf. Acesso em29 Setembro 2016. 
ENES, C. C.; SLATER, B.2010. Obesidade na adolescência e seus principais fatores determinantes. Revista Brasileira de Epidemiologia, v. 13, n. 1, p. 163-171, mar.

https://repositorio.ufrn.br/jspui/bitstream/123456789/13239/1/LarissaMJS_TESE.pdf. Acesso 29 Setembro 2016.

INSTITUTO BRASILEIRO DE GEOGRAFIA E ESTATÍSTICA - IBGE. Indicadores sociodemográficos e de saúde no Brasil. 2009a. 152p. Disponível em: <http://www.ibge.gov.br/home/estatistica/populacao/indic_sociosaude/2009/indicsaude.pdf >. Acesso em: 20 jan. 2012.

MAGALHÃES. Cultivo do Camarão Marinho Litopenaeusvannamei (BOONE, 1931) em sistema multifásico.2004. Dissertação (Mestrado em Recursos Pesqueiros e Aquicultura), Universidade Federal Rural de Pernambuco, Recife.2004. Disponível em http://oasisbr.ibict.br/vufind/Record/AGRE_1da11a64b906fc09082dcfaefb6a5c26. Acessado em 12 junho 2015.

ONOYAMA, 2006 appudSOUZA.J.F; BITENCOURT.N.N. et. al. Desenvolvimento e caracterização físico-química e sensorial de nuggets formulados com concentrado protéico de pescado-MARINE BEEF. Disponível em www.scientiaplena.org.br. Acessado em 04 junho 2015.

PINTO 2014. Relatório de estágio, apresentado ao Curso de Engenharia de Pesca da Universidade Estadual do Maranhão; 2014

ROCHA, 2011. Dimensão da cadeia produtiva da carcinicultura brasileira. Disponível em http://abccam.com.br/site/wp-content/uploads/2013/12/Dimens\%C3\%A3o-da-Cadeia-Produtiva-daCarcinicultura-Brasileira-JUN-2012.pdf. Acessado em 05 junho 2015.

ROSA; FERRANDIN; SOUSA. Desenvolvimento de nuggets de filé e polpa de tilápia com adição de linhaça (Linum usitatissimum $\quad$ L.). Disponível em http://repositorio.roca.utfpr.edu.br/jspui/bitstream/1/837/1/MD_COALM_2012_1_09.pdf. Acessado em de junho 2015.

SANTOS. Obtenção de produtos derivado de pescado elaborados a partir da utilização de cmscarne Mecanicamente separada. Revista SODEBRAS - Volume 8 - Nº 94 - Outubro/ 2013, p 3842. 
SEABRA. Camarão litopanaeus vannamei: componentes de importância nutricional na carne e nos resíduos do beneficiamento.

SOUZA. Avaliação da composição centesimal de empanados de frango do tipo "nuggets" submetidos a diferentes processamentos térmicos e aqueles provenientes de redes de "fast food". Disponível em file://C:/Users/kathe/Downloads/Dissertacao\%20Final\%20Patricia.pdf. Acesso em 17 Setembro de 2016. 